\title{
Reflexiones sobre la
}

infraestructura y el uso de sistemas inteligentes en la logística

Memorias del I Seminario Internacional de Logística

Giovanny Alexander Baquero Villamil Francisco Javier Caballero Otálora Javier Plutarco Castañeda Torres Andrés Ignacio Zamudio Castro

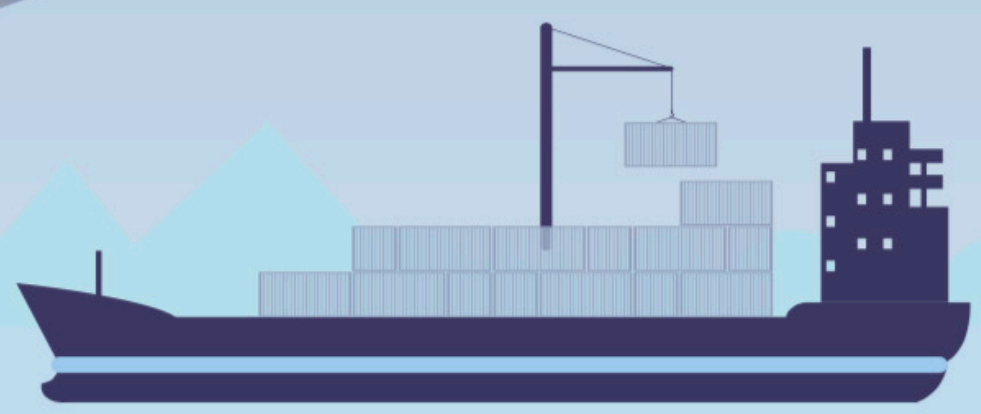




\section{REFLEXIONES SOBRE LA}

\section{INFRAESTRUCTURA Y EL USO}

\section{DE SISTEMAS INTELIGENTES \\ EN LA LOGÍSTICA}

MEMORIAS DEL I SEMINARIO INTERNACIONAL DE LOGÍSTICA

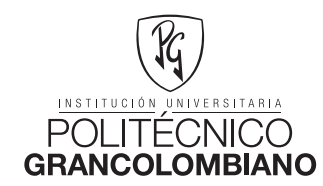

Giovanny Alexander Baquero Villamil

Francisco Javier Caballero Otálora Javier Plutarco Castañeda Torres Andrés Ignacio Zamudio Castro 
(c) Institución Universitaria Politécnico Grancolobiano

Reflexiones sobre la infraestructura y el uso de sistemas inteligentes en la logística.

Memorias del I seminario internacional de logística

ISBN: 978-958-8721-59-0

E-ISBN: 978-958-8721-46-0

Septiembre de 2017

Bogotá, Colombia

Editorial Politécnico Grancolombiano Av. Caracas No. 63-55, Piso 4

PBX: 7455555 Ext. 1171

editorial@poligran.edu.co

\section{Facultad de Ingeniería y Ciencias Básicas}

\section{Autores}

Giovanny Alexander Baquero Villamil Andrés Ignacio Zamudio Castro

Institución Universitaria Politécnico Grancolombiano

Francisco Javier Caballero Otálora

Corporación Universitaria Iberoamericana

Javier Plutarco Castañeda Torres

Fundación Universitaria del Área Andina

Lider de Publicaciones

Eduardo Norman Acevedo

Analista de Producción Editorial

Paulo Mora Noguera

Corrección de Estilo

Hernán Darío Cadena

Baquero Villamil, Giovanny Alexander
Reflexiones sobre la infraestructura y el uso de
sistemas inteligentes en la logística: memorias del I
seminario internacional de logística / Giovanny
Alexander Baquero Villamil; Francisco Javier
Caballero Otálora; Javier Plutarco Castañeda Torres
y Andrés Ignacio Zamudio Castro; lider de
publicaciones, Eduardo Norman Acevedo. - Bogotá
D.C.: Editorial Politécnico Grancolombiano, 2017.
66 p.; 14.6x 22.2 cm.
Incluye referencias bibliográficas.
ISBN: $978-958-8721-59-0$
E-ISBN: $978-958-8721-46-0$
1. Transporte -- Logística --Colombia 2.
Transporte por carretera -- Colombia 3. Río
Magdalena - Nave- gabilidad -- Colombia 4.
Transporte-- Tecnologías de la información y
comunicación. TIC 5. Transporte -- Congresos,
conferencias. I. Norman Acevedo, Eduardo. II.
Institución Universitaria Politécnico
Grancolombiano. Facultad de Ingeniería y
Ciencias Básicas. III. Tít.
SCDD 388.04 Institución Universitoria Politécnico Grancolombiano.

\section{Armada Electrónica}

Santiago Arciniegas Duarte

\section{Impresión}

Xpress Estudio Gráfico y Digital S. A.

\section{¿Cómo citar este Libro?}

Baquero Villamil, G. A., Caballero Otálora, F. J., Zamudio Castro, A. I., \& Castañeda Torres, J. P., (2017), Reflexiones sobre la infraestructura y el uso de sistemas inteligentes en la logística. Memorias del I seminario internacional de logística, Bogotá: Editorial Politécnico Grancolombiano.

La editorial Politécnico Grancolombiano pertenece a la Asociación de Editoriales Universitarias de Colombia, ASEUC.

El contenido de esta publicación se puede citar o reproducir con propósitos académicos siempre y cuando se dé cuenta de la fuente o procedencia. Las opiniones expresadas son responsabilidad exclusiva de los autores. 


\section{Tabla de contenido}

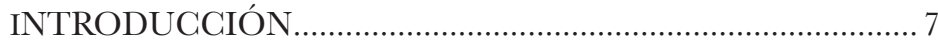

CAPÍTULO I: Navegabilidad del río Magdalena ......................... 10

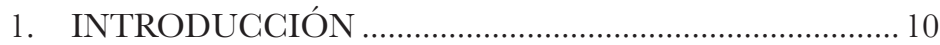

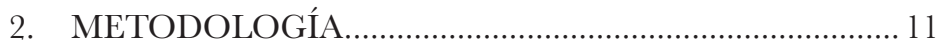

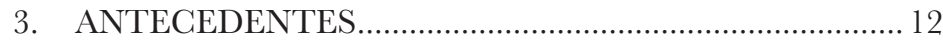

4. PROYECTOS DE DESARROLLO EN

INFRAESTRUCTURA FLUVIAL DEL RÍO

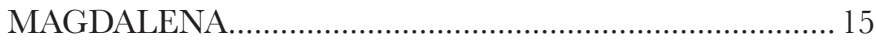

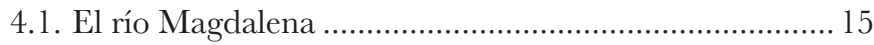

4.2. Estado actual del corredor fluvial y sus puertos............. 16

4.3. Puertos Fluviales ............................................................ 17

4.4. CONPES 3758: plan para restablecer la navegabilidad

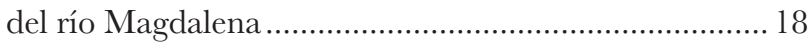

4.5. Proyectos de desarrollo en infraestructura ....................... 20

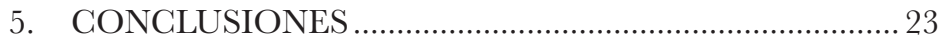

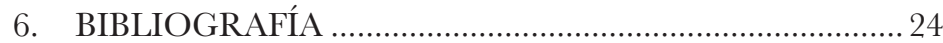

CAPÍTULO II: Aplicación de los sistemas inteligentes de información en transporte por carretera de equipo petrolero ....... 29

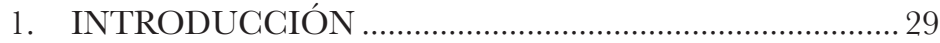

2. EL TRANSPORTE GARRETERO EN COLOMBIA ....... 30

3. SISTEMAS INTELIGENTES DE TRANSPORTE ............33

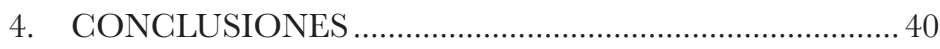

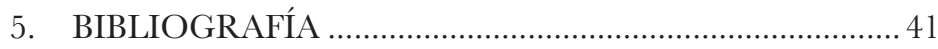


CAPÍTULO III: Tecnologías de la información y las

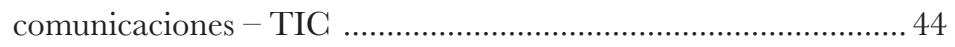

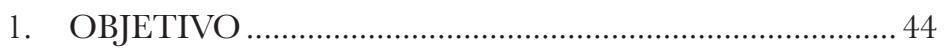

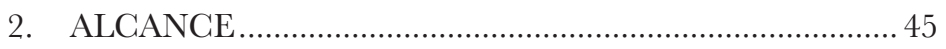

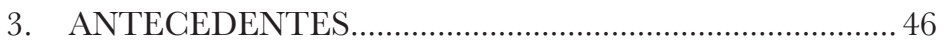

4. PLAN NAGIONAL DE TEGNOLOGÍAS DE LA INFORMACIÓN Y LAS COMUNICACIONES (PNTIC)

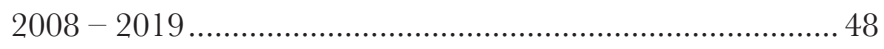

5. INDICADORES DEL SUBSISTEMA DE TEGNOLOGÍAS DE LA INFORMACIÓN Y LAS GOMUNICACIONES -

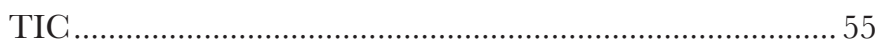




\section{INTRODUCCIÓN}

Las tecnologías de la información y las comunicaciones son cada vez más importantes y determinantes en el desarrollo económico y social de un país. Es así como por medio de diferentes estudios encabezados por la Unión Internacional de Comunicaciones se realiza la correlación entre la penetración del internet y la tasa de crecimiento del PIB (UIT, 2012). Adicionalmente son un medio para lograr el cumplimiento de los objetivos del milenio, específicamente en la erradicación de la pobreza, la universalidad de la educación, la equidad de género, la salud infantil entre otros (UIT, 2014).

Es así como las TIC son transversales en el desarrollo y se encuentran integradas directamente con la logística, ya que por medio de esta se han implementado procesos cada vez más eficientes que les permiten a las empresas ser más competitivas sin importar su tamaño. Adicionalmente, mediante su integración en la logística se ha logrado desarrollar nuevos mercados, como el e-commerce, llegando a cumplir con las expectativas de los clientes en el lugar correcto, 
al tiempo correcto, en el estado correcto, al costo correcto y con el producto correcto.

En este orden de ideas, la Corporación Universitaria Iberoamericana, la Institución Universitaria Politécnico Grancolombiano, la Fundación Tecnológica Colombo-Germana y la Fundación Universitaria del Área Andina tomaron como eje central del I Seminario Internacional de Logística "La logística como aliado estratégico del e-commerce" para analizar desde un punto de vista profesional y académico la forma en que se pueden cumplir los objetivos organizacionales por medio de la utilización de las TIC en un campo específico como es el de la logística, permitiendo a las empresas alcanzar la globalización ${ }^{1}$ de una forma integral al tener el flujo continuo en todos sus procesos, permitiendo la trazabilidad tanto de los productos como de los medios de transporte, pero para poder cumplir con los objetivos de la logística de relacionar a proveedores con los clientes con un costo logístico adecuado es necesario contar con los factores que le permiten su desarrollo, entre los que se encuentra la Infraestructura, la cual se ha determinado como una de las causas del bajo desempeño logístico, el cual ubica al país en el puesto 108 según el Foro Económico Mundial para el año 2014-2015 (WEF, 2014), ya que aún no se ha logrado desarrollar en el país el transporte multimodal, especialmente aprovechando el modo de transporte fluvial por el rio Magdalena. Adicionalmente se evidencia un deterioro en materia de calidad de la infraestructura frente a referentes internacionales. Es así como desde el Consejo Privado de Competitividad se realizan recomendaciones para desarrollar nuevos modos de transporte y establecer plataformas logísticas (Consejo Privado de Competitivi-

1 Globalización: es un término que guarda estrecha relación con la palabra integración (integración de países, regiones, mercados, economías, costumbres, etc.), y es un proceso que se ha venido dando a nivel mundial, en el cual muchos de los aspectos de la vida humana de unos lugares se han ido relacionando e interconectando con los de otros y, en general, con el mundo entero. 
dad, 2015), que le permitan al país una mayor competitividad en el campo internacional; este tema también fue analizado en el marco del I Seminario Internacional de Logística.

Bibliografía

- Cámara Colombiana de la Infraestructura. (2014). Colocación de Bonos y Financiamiento. Bogotá: Infraestructura y Desarrollo.

- Consejo Privado de Competitividad. (2015). Informe Nacional de Competitividad 2014-2015. Bogotá: Zetta Comunicaciones.

- UIT. (2012). Impact of Broadband on Economic. Geneva: Unesco.

- UIT. (2014). The state of broadband: Broadband. Geneva: Unesco.

- WEF. (2014). Global Competitiveness Report. Geneva: World Economic Forum. 


\section{CAPÍTULO I}

\section{NAVEGABILIDAD DEL RÍO MAGDALENA}

Autor: Giovanny Alexander Baquero Villamil

\section{INTRODUCCIÓN}

Una de las propuestas principales del presidente Juan Manuel Santos en su segundo mandato es la de estimular el comercio por el río Magdalena, debido a que está considerado como el principal afluente del país, dada su longitud y recorrido por diferentes departamentos.

El Magdalena es utilizado en la actualidad para el trasporte de hidrocarburos, carbón y productos a granel, pero este no cuenta con un gran desarrollo en infraestructura, esto se debe a la poca inversión por parte del Estado, las restricciones impuestas por el mismo río y el desaprovechamiento de las ventajas operacionales del transporte fluvial.

En el año 2014 el gobierno firmó el contrato para la recuperación de la navegabilidad del río Magdalena por un valor cercano a los 2.5 billones de pesos, este contrato incluía la construcción de alrededor 
de 160 obras civiles de encauzamiento entre Puerto Salgar y Barrancabermeja, con el mantenimiento y su operación.

Al finalizar los trece años y medio que se tiene estimada la duración del proyecto, desde Puerto Salgar hasta Barranquilla, en esos 908 kilómetros de intervención del río se debe haber logrado incrementar la capacidad de transporte de carga de 1.5 millones de toneladas a 6 millones. La empresa contratada debe también realizar labores de monitoreo satelital y de mantenimiento de dragado.

Por todo lo anterior, el propósito de este estudio es ilustrar la situación general del río Magdalena en cuanto a inversión y desarrollo de obras de infraestructura física, con el fin de fortalecer y habilitar este corredor fluvial. Esto describiendo su desarrollo por los principales tramos del afluente comprendidos entre el puerto de Puerto Salgar y la salida del río Magdalena, y tomando como referencia el documento CONPES 3758 propuesto para la ejecución de las nuevas obras de desarrollo.

\section{METODOLOGÍA}

El grupo E-TRANSCOL en la identificación del corredor logístico nacional para el transporte de carga, ha identificado como uno de sus objetivos primarios el "Diseñar un modelo prototipo de corredor logístico que permita formular estrategias y arreglos institucionales, en relación con el cual se puedan identificar los cambios necesarios que permitan mejorar el desempeño logístico del sector transportador de carga, con base en escenarios futuros deseados y no deseados en los principales corredores del país". Para el logro del mismo identifica como actividad necesaria el "Desarrollar un sistema de indicadores 
logísticos que permita monitorear el desempeño del sistema logístico de carga, específicamente en el corredor ideal” (E-TRANSCOL, 2014).

Debido a esto, se desarrolla una fase de investigación que pretende identificar las variables relevantes para el corredor fluvial del río Magdalena, por su importancia para el desarrollo de diferentes sectores que lo han utilizado o los que estén interesados en utilizarlo en el futuro.

El desarrollo metodológico que se realizó fue primero una corta reseña histórica del río e importancia para el país, luego se describieron las medidas implementadas para el mejoramiento del desempeño del corredor logístico del río Magdalena con base en los objetivos propuestos en el documento CONPES 3758. Al describir el desarrollo de la infraestructura se realizó una descripción del estado de los puertos fluviales del corredor en el tramo seleccionado entre el puerto de Puerto Salgar y la salida del río Magdalena en el Caribe colombiano.

Posterior a ello se realizó una descripción del desarrollo e implementación de los planes de inversión, para luego concluir mostrando un planteamiento general de la situación del río en cuanto avance de infraestructura y los posibles escenarios futuros para mejorar la logística fluvial en el país.

\section{ANTECEDENTES}

El modo de transporte fluvial es una de las principales formas de movilidad. Su importancia radica en la posibilidad de mover carga con bajos costos de operación, en grandes volúmenes y con la capacidad de conectar dicho material con diversos modos de transporte, como 
son el terrestre, aéreo y ferroviario (Crainic y Kim, 2007). Adicional a esto, el modo de transporte fluvial permite establecer altos niveles de seguridad y movilidad, por medio del desarrollo de redes logísticas para la movilización de mercancías y puntos de carga y descarga de las mismas por medio de la interconexión con zonas de transbordo y puertos (Miller-Hooks, 2009; Tuite, 2007). Esto requiere una gran inversión de recursos destinados al mejoramiento de las operaciones logísticas, objetivos propuestos en el documento CONPES 3547 para la adecuación de dicho modo de transporte, lo cual será el eje central de este estudio, explicando claramente los requerimientos y los proyectos que se han venido desarrollando durante los últimos años en el país.

El río Magdalena es conocido como el principal afluente de Colombia, debido a sus $1.550 \mathrm{~km}$ de extensión y que atraviesa medio país, principalmente el occidente, junto a las cordilleras central y occidental. Su extensión corresponde al 24\% de la superficie del país, conectando a los departamentos de Caldas, Atlántico Cundinamarca, Antioquia, Bolívar, Santander y Magdalena, pero con solo 1.024 km aptos para la navegación de vehículos de carga (CONPES 3758).

En los siglos XV y XVI el río Magdalena era el principal medio de transporte de carga del caribe hacia el interior del país y viceversa (Museo Nacional, 2010).

Para los siglos XVIII y XIX con las instalaciones de grandes centros urbanos en localizaciones lejanas a la ladera del río y la elaboración de los caminos de herradura, el trasporte de carga por medio fluvial empezó a perder importancia con el paso de los años. (Museo Nacional, 2010).

Hacia 1922 se desarrollaron cambios como consecuencia de la puesta en operación de la refinería de Barrancabermeja y la llegada 
del combustible "fuel oil", que remplazó la leña y el carbón como combustible de la flota; el comercio del país tenía proyecciones de rápido desarrollo, con importaciones aproximadas a los 350 mil ton/ año, contando con una flota de 97 buques a vapor (CGI, 2008).

El desarrollo del sector de los hidrocarburos ha ido de la mano con el desarrollo del río Magdalena y su vinculación con el puerto de Barrancabermeja, el cual se ha especializado en el embarque de barriles de derivados de hidrocarburos para ser transportados a los puertos de la zona caribe para su posterior comercialización o exportación.

Registros históricos presentan que en 1956 se movilizó cerca de 2 millones de ton/año y más de 360 mil pasajeros, esto debido a la mejora tecnológica en la flota de buques propulsados por motores diésel, mejorando aspectos como velocidad y capacidad de los buques, y comodidades para la tripulación y los pasajeros (CCI, 2008).

En la historia del desarrollo del río Magdalena se han dado múltiples intentos de aprovechamiento del río, pero sus características de navegación y el desarrollo multimodal han sido los principales obstáculos. Se han iniciado varios proyectos con grandes metas pero que por malas gestiones no se han logrado concluir y quedan como obras inconclusas (FLUIDIS, 2007).

En la década de 1960, el río Magdalena fue perdiendo su vigencia como medio de carga con la llegada del ferrocarril del Pacífico y con el desarrollo de carreteras y el transporte aéreo de carga.

En 1991, con la nueva constitución se realizó un ajuste al Ministerio de Transporte, dándole herramientas para la creación de organismos como la Corporación Autónoma Regional del Río Grande de la Magdalena - CORMAGDALENA, encargada de los aspectos técnicos y de control del río (CGI, 2008). 
Instituciones vinculadas con el transporte fluvial como CORMAGDALENA han venido desarrollando estudios como el "estudio de demanda de transporte del sistema fluvial del río Magdalena y evaluación beneficio costo de la instrumentación de un esquema de reactivación de la navegación fluvial", desarrollado en el 2001 como una herramienta para justificar la inversión sobre el río y reactivar su operación.

En los últimos años se han venido gestionando proyectos con miras a despegar y fortalecer el transporte fluvial existente en la actualidad, como lo es el proyecto de locomotora de la infraestructura propuesto por el gobierno nacional o los documentos CONPES 3758.

Los proyectos de desarrollo en el río Magdalena han captado la atención de importantes navieras que desean invertir para aprovechar el potencial mercado que está a la espera de las inversiones en infraestructura por parte del gobierno nacional (Sena, 2006).

\section{PROYECTOS DE DESARROLLO EN} INFRAESTRUCTURA FLUVIAL DEL RÍO MAGDALENA

\subsection{El río Magdalena}

Colombia es un país destacado por su riqueza hídrica, que cuenta con una red fluvial de longitud total de $24.725 \mathrm{~km}$, de los cuales el río Magdalena cuenta con una longitud de $1.550 \mathrm{~km}$ desde su naci- 
miento en la laguna de La Magdalena, hasta la desembocadura en el mar Caribe.

Navegable en un $66 \%$ de su longitud total, ocupa el $24 \%$ de la superficie continental del país, su uso no se limita al transporte de mercancías, pues es utilizado para generar el 70\% de la producción hidroeléctrica del país y el 95\% de la termoeléctrica. Registra el mayor movimiento fluvial del país con $44,69 \%$, y un $0,6 \%$ de la carga total que se moviliza en el país.

El tramo seleccionado entre Puerto Salgar, Cundinamarca y la desembocadura del río en Barranquilla cuenta con 909 km navegables y habilitados para el transporte de carga o pasajeros (CONPES 3758).

\section{2.- Estado actual del corredor fluvial y sus puertos}

El río se encuentra dividido en tramos, bajo los cuales se pueden desarrollar proyectos de desarrollo celebrados con particulares. Algunas de las obras más sobresalientes que se encuentran contratadas son:

Proyecto: mantenimiento del sector Barrancabermeja - Calamar, como un convenio con Ecopetrol, para realizar obras de dragado en el río Magdalena, en el tramo comprendido entre Barrancabermeja y Calamar (excluyendo Pinillos), costo $\$ 6.000$ millones.

Proyecto: dragado hidráulico en la jurisdicción del municipio de Pinillos, con las dragas "CORMAGDALENA 1" y "DHC-9", costo $\$ 1.590$ millones.

Proyecto: dragado e interventoría para el mantenimiento de la profundidad del canal navegable en el río Magdalena en el sector comprendido entre Puerto Salgar 
La Dorada (Cundinamarca / Caldas) - Barrancabermeja (Santander), costo $\$ 8.123$ millones.

Proyecto: mantenimiento de la profundidad del canal navegable del río Magdalena mediante dragado en el Puerto de Barranquilla, costo $\$ 9.479$ millones.

\section{3.- Puertos Fluviales}

El estado de los puertos del río es el factor más preocupante, debido a que su capacidad es rebasada por la demanda estimada para el corredor, y la baja eficiencia en temas importantes como el tamaño, servicio y calidad, lo cual permite proyectar que si no se realizan inversiones en el futuro la operación fluvial no va a tener buenos logros.

Factores importantes con problemas en los puertos son los siguientes:

- Bodegas.

- Los muelles inapropiados.

- Falta de patios de almacenaje.

- Servicios complementarios.

- Los equipos tecnológicos desactualizados (CONPES 3744).

El río cuenta con trece concesiones portuarias, con inversiones estimadas cercanas a los $\$ 34$ mil millones y otras nueve solicitudes de concesión con una inversión de $\$ 190$ mil millones de pesos, lo que ayudará al desarrollo y mejoramiento de las condiciones actuales de los muelles existentes (CCI, 2008). 
4.4.- CONPES 3758: plan para restablecer la navegabilidad del río Magdalena

En el documento CONPES 3758 se plantea un plan de acción partiendo del año 2013 con el objetivo de restablecer la navegabilidad en el río Magdalena. Con dos objetivos claros: el primero a corto plazo, mejorar las condiciones de navegabilidad del río, y, en el mediano plazo, lograr el desarrollo de este corredor fluvial como un corredor logístico intermodal (Plan Nacional de Desarrollo hacia la Prosperidad Democrática: Visión 2010 - 2014).

\section{Los objetivos del Plan para restablecer la navegabilidad del río Magdalena son (Roda, 2010):}

- Mejorar la navegabilidad del río Magdalena por medio de adecuadas inversiones en infraestructura y ayudas a la navegación.

- Consolidar la oferta de infraestructura logística integrada en los diferentes nodos estratégicos.

- Permitir una navegación segura y continua durante las 24 horas del día, para lo cual se debe ampliar la cobertura del Sistema de Asistencia Satelital (SNS).

- Mitigar impactos ambientales que actualmente afectan la condición ecológica de la cuenca y del recurso hídrico sumado a la afectación de sus usos y aprovechamientos socioeconómicos, como lo es la navegabilidad. 


\section{Se busca articular los anteriores objetivos con el plan, que está compuesto de tres ejes:}

- Esquema de Asociación Público Privada-APP,

- Componente físico - Intervención en el río,

- Acciones complementarias - Desarrollo y fortalecimiento.

Esquema de Asociación Público Privada -APP: mediante la elaboración de los análisis necesarios para ejecutar el proyecto bajo un nivel de conformidad con los requisitos y procedimientos contemplados en la Ley 1508 de 2012 y sus decretos reglamentarios, los cuales logren hacer un traslado eficiente de los riesgos buscando maximizar el río como una gran arteria de transporte.

Componente físico: contempla una serie de intervenciones en el río orientadas a la ampliación de kilómetros navegables, en búsqueda de mejorar las condiciones de navegabilidad sobre el afluente (Liedtke, 2009).

Acciones complementarias orientadas hacia el desarrollo y fortalecimiento: enfatizan en el desarrollo de obras alternas al río que fortalecerán los servicios de transporte intermodales y logísticos.

Dada la naturaleza del estudio que se pretende abordar, se realiza un énfasis en el componente físico del plan de acción descrito por el CONPES 3758. 


\section{5.- Proyectos de desarrollo en infraestructura}

Con el objetivo de mejorar las condiciones de navegabilidad, se realizó un análisis del sistema de transporte en el corredor del río Magdalena, los volúmenes, pesos y tipos de carga movilizado, el origen y destino y los costos de operación de los modos fluvial en comparación con el carretero y férreo de la zona comprendida por el corredor (Peñaloza Miguel, Infraestructura y Logística).

Bajo la estimación de demanda de carga a movilizar por cada puerto, se definieron cuáles serían los beneficios e ingresos esperados para actor, debido a la reactivación de los puertos, determinando en cada caso la relación de costo - beneficio que se puede presentar además de otras medidas o indicadores. Este análisis está basado en el estudio desarrollado por CORMAGDALENA en el cual se concluyó que es factible el desarrollo de la navegación desde Barranquilla hasta Puerto Salgar técnica y económicamente, teniendo un estimado de capacidad máxima de circulación por el corredor de 550 millones de toneladas/año (CGI, 2008).

De acuerdo con lo mencionado, las acciones de intervención en el río se dividieron en 15 tramos de acuerdo con el nivel de atención necesaria, y la asignación prioritaria asignada por el estudio realizado por CORMAGDALENA. Esto con el fin de definir un canal navegable y que permita una profundidad de 7 pies en el tramo de $256 \mathrm{~km}$ (CONPES 3758).

A. Navegabilidad en $256 \mathrm{~km}$ : desarrollo de obras de encauzamiento en el tramo Puerto Salgar - La Dorada - Barrancabermeja. CORMAGDALENA identificó como prioritario el tramo comprendido entre Puerto Salgar - La Dorada y Barrancabermeja, que cuenta con una extensión de $256 \mathrm{~km}$. 
Esto para mejorar las condiciones de navegabilidad del río y así permitir el aprovechamiento del corredor para el transporte de carga del interior del país hacia el mar Caribe o viceversa (CONPES 3758).

\section{Descripción de las obras:}

- Canal navegable: es necesario realizar ajustes al canal existente en buena parte de su recorrido, para mejorar radios, anchuras, y profundidades que cumplan con los estándares de navegación.

- Estructuras de encauzamiento: las obras consisten en un conjunto de revestimientos en trinchera, diques de alineamiento y enrocado, y anclajes de diques de enrocado, esto para minimizar la dispersión de los caudales en tiempos de sequía y concentrarlos en un solo canal principal más profundo y operativo.

- Detalles de señalización y paso de canoas: los diques tendrán pasos de canoas para no interferir con el desarrollo propio de las comunidades ribereñas, que dependen de la pesca en el río.

Las obras de encauzamiento permanentes, que permitan el tránsito de convoyes con mayor capacidad de carga, entre estas obras se encuentran:

Revestimientos en trincheras: se usan para revestir orillas que están en proceso de erosión, o para conformar alineamientos futuros de la orilla. Este tipo de estructuras es fundamental para evitar la divagación del cauce y poder fijar y estabilizar el canal navegable en curvas. 
Diques de alineamiento en enrocado: son estructuras que se construyen en el fondo del río para mejorar o para dirigir el flujo en cruces y áreas donde la orilla es demasiado baja, para permitir la construcción de un revestimiento en trinchera.

Diques de enrocado para control de flujo en aguas bajas: se utilizan para control del flujo de aguas bajas en brazos menores, orientar las líneas de corriente, promover el desarrollo de nuevas orillas, y servir como pantallas hacia tierra en complemento de la acción de los revestimientos de fondo.

Anclajes de diques de enrocado: sirven para empotrar las estructuras en los barrancos laterales del río.

Desarrolladas las obras de encauzamiento, se garantizará que convoyes tipo R-2B-2B-2B (Remolcador más seis barcazas en tres hileras de a dos), con capacidad máxima de carga de 6.000 y 7.200 toneladas en cada uno de los remolcadores, y que estos puedan transitar en condiciones permanentes y seguras de navegabilidad durante los 365 días del año (Asoportuaria, 2013).

Estas obras tienen un costo aproximado de USD \$ 387,5 millones para los $256 \mathrm{Km}$ del tramo Puerto Salgar - Barrancabermeja, arrojando un costo promedio de USD $\$ 1,55$ millones $/ \mathrm{Km}$.

B. Mejoramiento de las condiciones de navegabilidad: dragados de mantenimiento en el tramo Puerto Salgar - La Dorada Bocas de Ceniza - Barranquilla (909 km).

Concluido el objetivo de aumentar la profundidad del corredor fluvial del río Magdalena en el tramo Puerto Salgar y Barrancabermeja, será necesario el garantizar las actividades de dragado a lo largo 
de todo el corredor desde Puerto Salgar - La Dorada hasta Bocas de Cenizas - Barranquilla con una longitud de 909 km.

Programa de dragado hidráulico para garantizar las condiciones de profundidad que habiliten la navegabilidad en el río, comenzando con el Tramo primeros dos (2) km, desde Bocas de Ceniza hacia el Puente Laureano Gómez, calado 40 pies, luego Tramo Canal de acceso, calado 37,5 pies, Tramo entre Barranquilla y Barrancabermeja (km 630), calado 7 pies, Tramo Barrancabermeja y Puerto Berrío, calado 6 pies, Tramo Puerto Berrío y Puerto Salgar, calado 4,5 pies.

En el año 2013 se transportaron alrededor de 950.000 toneladas de carga. Para el año 2014, la meta es llegar a 1,2 millones. Posteriormente, con las acciones realizadas, la meta es llegar a los 6 millones anuales, permitiendo transportar hasta cinco veces más barato vía fluvial que lo que cuesta hacerlo en modo carretero.

\section{CONCLUSIONES}

Las obras desarrolladas por parte del gobierno nacional han sido grandes, pero no suficientes con el objetivo de permitir la navegabilidad y el transporte de materiales, mercancías y personas por modo fluvial en el río Magdalena. La importancia de dicho corredor radica en la posibilidad de conexión del territorio nacional por medio de los más de $1.500 \mathrm{~km}$ de recorrido. Como elementos fundamentales de esta investigación, se definen los siguientes elementos:

- El modelo utilizado para superar las características difíciles del río es la replicación de modelos funcionales aplicados en otras partes del mundo. 
- El interés por fomentar el desarrollo de corredores fluviales por parte del gobierno, al observar que no cuenta con todo el dinero requerido para las inversiones, diseña planes con participación de entidades privadas, lo que favorecerá el fortalecimiento de los mismos mediante la inversión y motivación de nuevos actores por usar estos servicios.

- Debido a los múltiples intentos de canalizar el río en años anteriores es recomendable dialogar con todos los interesados y buscar los objetivos comunes para que se estimule el cumplimiento de los proyectos hasta feliz término.

- Es recomendable realizar seguimiento a los diferentes contratos firmados por el gobierno para verificar si se está cumpliendo con los objetivos o se deben realizar ajustes, esto por los altos montos comprometidos y la importancia del río como canal de transporte.

\section{BIBLIOGRAFÍA}

- Allen, J., Tanner, G., Browne, M., Anderson, S., Christodoulou, G., y Jones, P. (n.d.). Modelling policy measures and company initiatives for sustainable urban distribution.

- ASOPORTUARIA (2013). Modelos de optimización de costos de transporte intermodal en el río Magdalena. 
- Bemeleit, B., Lorenz, M., Schumacher, J., y Herzog, O. (n.d.). Risk Management in Dynamic Logistic Systems by Agent Based Autonomous Objects. Dynamics in Logis TIC.

- Browne, M., Whiteing, A., y Allen, J. (n.d.). City logisTIC: The continuing search for sustainable solutions. Global Logis TIC and Distribution Planning: Strategies for Management.

- Cámara colombiana de infraestructura (2008). Seguimiento a proyectos de infraestructura, informe dirección técnica, transporte fluvial: Rio Magdalena - Canal del Dique.

- Cámara colombiana de infraestructura (2008). Seguimiento a proyectos de infraestructura, modo fluvial.

- CONPES 3547. (2008). Ministerio de transporte.

- CONPES 3489, Política Nacional de Transporte Público Automotor de Carga. Ministerio de Transporte.

- CONPES 3758 (2013). Plan para restablecer la navegabilidad del río Magdalena.

- CONPES 3744 (2013). Política portuaria para un país más moderno.

- CONPES 3568 (2008). Seguimiento al CONPES 3547 del 27 de octubre de 2008: Política Nacional Logística. Ministerio de transporte. 
- Cormagdalena, (2002). Adecuación de los Principales Puertos del río Magdalena, Recuperado de: documentos CORMAGDALENA

- CORMAGDAlENA (2011). Plan de acción 2012 - 2014 - la gran vía del transporte nacional.

- Crainic, T. G., Y Kim, K. H. (2007). Transportation. Handbooks in Operations Research and Management Science Vol. 14.

- FLUIDIS, (2007) Proyecto FFEM CORMAGDALENA plan de manejo de la cuenca del río Magdalena - Cauca - segunda fase.

- Liedtke, G. (2009). Principles of micro-behavior commodity transport modeling. Transportation Research Part E: Logis TIC and Transportation Reviewe, 45(5), 795- 809.

- Meixell, M. J., y Gargeya, V. B. (2005). Global supply chain design: A literature review and critique. Transportation Research Part E: Logis TIC and Transportation Reviere, 41 () 531-550.

- Miller-Hooks, E., Chen, L., Nair, R., y Mahmassani, H. (2009). Security and Mobility of Intermodal Freight Networks. Transportation Research Record: Fournal of the Transportation Research Board, 2137 (2137), 109-117.

- Naviera Fluvial Colombiana, (2009). Transporte de carga intermodal por el río Magdalena 
- Pablo Roda Fornaguera, (2010) Plan de Inversiones en Infraestructura de Transporte. Retrieved From Documentos Ministerio de Transporte.

- Peñaloza Miguel. Infraestructura y Logística: Avances para la Competitividad. Alto Consejero para la competitividad y las Regiones

- Ministerio de Transporte, (1999). Resolución 0000666 Reglamento de Luces y Señales de Navegación Fluvial.

- Plan Nacional de Desarrollo hacia la Prosperidad Democrática: Visión 2010 - 2014. Sector Transporte

- SENA, (2006). Caracterización Ocupacional de los Servicios Portuarios. Recuperado de: http://observatorio.sena.edu.co/ mesas/01/SERVICIOS\%20PORTUARIOS.pdf

- SENA, Subsector transporte fluvial, (2007). Estudio de Caracterización del

- Transporte Acuático. Recuperado de: http://observatorio.sena. edu.co/mesas/01/TRANSPORTE\%20ACUATICO.pdf

- Superintendencia de Puertos y Transporte, Luz María Villa Roldán, (2010). Informe de Análisis de la Infraestructura Portuaria Marítima y Fluvial en el País en el año 2010. Recuperado de: http://www.supertransporte.gov.co/documentos/2014/ delegada $\% 20$ puertos/caracterizacion $\% 20$ puertos/Informe $\% 20$ de $\% 20$ Analisis $\% 20 \mathrm{de} \% 201 \mathrm{a} \% 20$ Infraestructura.pdf 


\section{CAPITULO I}

- Tuite, P. M. M. (2007). A framework for evaluating risk to the transportation network from terrorism and security policies. International Journal of Critical Infrastructures, 3 (3/4), 389. 
CAPÍTULO II

APLICACIÓN DE LOS

SISTEMAS INTELIGENTES

DE INFORMACIÓN EN

TRANSPORTE POR

CARRETERA DE EQUIPO

PETROLERO

Autores: Francisco Javier Caballero Otálora y Javier Plutarco Castañeda Torres

\section{INTRODUCCIÓN}

El transporte carretero en Colombia se ha convertido en el modo de transporte de carga por excelencia, dejando de lado otros modos como el férreo y fluvial, pero si bien es cierto que es el modo de transporte por excelencia no es menos cierto que el mismo carece 
de la infraestructura y tecnología necesaria para hacer del mismo un transporte eficiente.

Las empresas de transporte carecen de innovación y su valor agregado es muy bajo, tanto que no existe una claridad respecto a la planeación de los despachos: todos los días a primera hora se están solicitando los vehículos necesarios para atender las rutas de la jornada, y la capacidad de respuesta de los transportadores se ve disminuida, a causa de no existir siempre la disponibilidad de vehículos (Cadena, 2013).

Los sistemas inteligentes de transporte permiten un uso planificado del transporte carretero y esto lo han entendido las organizaciones del sector que trabajan con empresas prestadoras de servicios petroleros, y por medio de la implementación de los mismos ofrecen un servicio diferenciado con un alto valor agregado.

\section{EL TRANSPORTE CARRETERO EN COLOMBIA}

El transporte juega un papel relevante en la economía, especialmente dentro del proceso de globalización, por ser factor determinante en la competitividad de los productos y servicios que el país puede ofrecer en los mercados internacionales, por su contribución en la producción industrial y agrícola, y por su aporte al incremento del bienestar individual al facilitar la movilidad y la accesibilidad a servicios básicos tales como educación y salud (Oficina Asesora de Planeación Min Transporte, 2005). 
El sector de transporte de carga representa la mitad o tres cuartas partes del costo logístico de las empresas colombianas. Hay varias razones que influyen en la alta participación del transporte en el costo logístico, siendo la falta de un sector de transporte de carga competitivo una de ellas (Consejo Privado de Competitividad, 2012). Esto también se ve afectado por la falta de coordinación entre los generadores de carga y el sector de transporte, por lo que cualquier intento para incrementar la competitividad de los segundos deberá incluir a los primeros. En el país, 75\% del parque automotor es propiedad de personas naturales y $17 \%$, de las empresas generadoras de carga.

Existe una atomización del mercado donde 20 empresas manejan entre el 75\% y 80\% de la carga, y los pequeños transportadores manejan un porcentaje mínimo, generando una desigualdad en cuanto a los ingresos, siendo perjudicados los pequeños transportistas (Consejo Privado de Competitividad, 2012).

La falta de competitividad del sector de transporte de carga no solamente se le puede atribuir al gremio en sí mismo, ya que el sector se caracteriza por ser altamente informal y poco innovador, predominando la ausencia de contratos entre las empresas transportadoras y los propietarios de los camiones y conductores. En otro aspecto, el parque automotor es obsoleto, la edad promedio de los vehículos es de 22 años y aproximadamente una tercera parte de estos tiene más de 30 años (Ministerio de Transporte, 2005). Lo anterior, además de generar problemas de seguridad vial y de la carga, genera externalidades negativas sobre el medio ambiente.

Al sector lo ha aquejado un exceso de regulación que ha redundado en menores niveles de eficiencia. Por ejemplo, la existencia de una tabla de fletes que definía un minimo nivel de precios para el transporte de carga terrestre en el país, no solo conllevaba la falta de incentivos por parte de las empresas de transporte para prestar 


\section{CAPITULO II}

servicios de mayor valor agregado a menores costos, sino que generaba incentivos para que actores formales se comportaran de manera informal, con el fin de evadir el pago del precio piso. Adicionalmente, esta tabla exacerbaba el problema de edad de los vehículos, en la medida en que permitía la rentabilidad - y, por tanto, la circulación- de vehículos viejos e ineficientes que de otra manera no hubiesen sido rentables bajo unas condiciones de mercado libre. De otra parte, a raíz del boom del petróleo (que se presentó hasta el año 2014) y de la falta de capacidad en oleoductos, la demanda por el uso de vehículos se incrementó, lo cual ha aumentado sustancialmente el costo de los fletes y ha reducido la disponibilidad de vehículos para los demás sectores de la economía. Si bien esta situación conlleva a incentivar el aumento del parque automotor por los mayores fletes, nuevamente el exceso de regulación, esta vez vía la exigencia de chatarrización, se convierte en un impuesto al incremento del número de camiones, por lo que se obstaculiza un eficiente ajuste de la oferta a las señales de mercado. Adicionalmente, la carencia de mano de obra calificada afecta la competitividad del sector. No existen suficientes planes de capacitación dirigidos a los transportadores, en particular a los microempresarios del transporte, lo cual implica la no utilización de buenas prácticas empresariales de estos agentes. A lo anterior se suma la falta de operatividad en red por parte de los transportistas. Las actividades individuales no se apoyan en nodos virtuales o fisicos de concentración de carga que permitan optimizar el volumen de esta, combinando los envíos de tamaño más reducido o coordinando los pedidos de retorno. Adicionalmente, existe mucho espacio para lograr optimizaciones en el manejo logístico, a través de una buena coordinación entre generadores y transportistas. Por ejemplo, actualmente un vehiculo con un conductor hace entre dos y tres viajes a la Costa, cuando este podría hacer cómodamente 4,75 viajes, reduciendo sustancialmente los costos. El Gobierno ha venido adelantando una serie de esfuerzos para mejorar la competitividad del sector. Es así como, mediante el Decreto 2092 de junio de 2011, se desmontó la tabla de fletes, lo cual es un paso adelante para el mayor desarrollo del sector, ya que permite la libre contratación entre los transportadores y los usuarios. Para hacer seguimiento al comportamiento del sector se creó el 
Sistema de Información de Costos Eficientes y el Observatorio Nacional Logístico, cuyo objetivo es servir de guía a los transportadores, las empresas de transporte y los generadores de carga, al momento de pactar los términos de negociación. Para acompañar el desmonte de la tabla, se tiene previsto impulsar un documento Conpes de Política de Renovación de Flota y Formalización del Sector, con el objetivo de tener una oferta y demanda de servicios de transporte equilibrada. En concordancia con lo anterior, el Ministerio de Transporte ha abierto mesas de concertación con la participación del sector privado para impulsar el desarrollo del sector de transporte (Consejo Privado de Competitividad, 2012).

\section{SISTEMAS INTELIGENTES DE TRANSPORTE}

El transporte generalmente representa el elemento individual más importante en los costos de la logística y competitividad de un país, ya que afecta en forma transversal a todas las estrategias desarrolladas por los gobiernos (Sanabria, 2008).

Contar con un sistema eficaz de transporte les permite a los países alcanzar niveles de desarrollo importantes que impactan directamente en las metas a desarrollar por parte de los gobiernos y debe ser una política de estado como la misma seguridad nacional (Cipoletta, 2010).

Los países desarrollados cuentan con sistemas de transporte evolucionados, mientras que los países en desarrollo sufren grandes deficiencias en su transporte, lo cual se refleja en los elevados costos de movilizar carga de los centros de producción a los centros de consumo, y que algunas zonas de estos países el transporte, tanto de pasajeros como de carga, se convierta en verdaderas gestas titánicas, afectando 
el nivel de vida de sus habitantes al no poseer buena educación, escasa comunicación, deficiencias en la prestación de servicios de salud, y su comercio se ve seriamente comprometido por las dificultades de acceso (Ballou, 2004).

El grado de desarrollo se logra con un principio que la sociedad ha utilizado desde que se percató que era necesario interrelacionarse con comunidades ubicadas en otros lugares y es el principio de la movilidad. La movilidad de las personas para interactuar, intercambiar culturas y conocimientos y, lo más importante en el desarrollo de cualquier sociedad, movilidad para cargar sus mercaderías y realizar intercambios de productos.

La movilidad inicia desde algo tan primitivo como la misma humanidad, cuando se tenían que movilizar de una región a otra para satisfacer sus necesidades básicas en la época de los nómadas. Posteriormente, cuando fueron sedentarios se dieron cuenta que debían intercambiar los productos propios de sus regiones con los de otras regiones generándose el trueque; para realizar esta función las comunidades primitivas utilizaban el suelo, el agua y hasta el aire tratando cada día mejorar sus niveles de vida (Ballou, 2004).

El desarrollo de nuevas tecnologías no se detiene y la humanidad sigue encontrando cada vez mejores sistemas de transporte para lograr reducir los tiempos de integración, los costos de desplazamiento, la comodidad y seguridad de las personas y de la carga (Cipoletta, 2010).

En la actualidad la sociedad tiene cada vez mejores vehículos de transporte terrestre, vehículos de transporte aéreo mucho más desarrollados, vehículos de transporte marítimo con mejores capacidades 
y el transporte masivo urbano como solución de la movilidad en los centros urbanos.

Con estos adelantos, prácticamente ya no se existe ningún tipo de producto que no se pueda transportar, y cada vez los sitios son más aislados y los tamaños de la carga son extradimensionados, pero si existe la demanda debe existir la oferta para cumplir con las necesidades para el desarrollo de los pueblos y del país en general (Ministerio de Transporte, 2005).

Este desarrollo ha obligado también a la sociedad y los gobiernos a rediseñar sus infraestructuras para adecuarlas a los medios de transporte actuales, las vías deben tener mayores especificaciones de peso, de desgaste, de ancho; al igual que los puentes y los puertos han tenido que ampliar sus estructuras para recibir vehículos de mayor tamaño (Sanabria, 2008).

$\mathrm{Al}$ existir una mayor cantidad de vehículos hace necesaria una regulación de tránsito y transporte que permita un desarrollo ordenado de esta actividad (Ministerio de Transporte, 2013)

Es por esto que la planeación en transporte terrestre en modo carretero se hace pieza fundamental de la logística, en cuanto que va establecer de una forma clara y ordenada cuál debe ser el movimiento que se va a desarrollar en los tiempos, recorridos, análisis de contingencias y peligros durante el desarrollo de la actividad de transporte.

En este escenario, los sistemas de información se entienden como un conjunto de aplicaciones de las tecnologías electrónicas, de comunicación y de información en el campo de transporte (Inglada, 2003). Se convierten en un factor fundamental para desarrollar dicha planeación de la forma más eficaz y eficiente posible. 
El objetivo de los sistemas inteligentes de transporte es incrementar el rendimiento y la productividad de vehículos, carreteras y sistemas de transporte; adicionalmente, coadyuvan en el cumplimiento de la legislación, específicamente la Ley 336 de 1996 y la ley 105 de 1993, que en todo momento buscan la seguridad, movilidad, accesibilidad, preservación ambiental, al entenderse el transporte como un servicio público vigilado por el estado colombiano.

Frecuentemente estas tecnologías se combinan entre sí con el fin de obtener beneficios superiores a la suma de los producidos por cada aplicación por separado.

Un aspecto sumamente relevante para su caracterización es que SIT $^{1}$ representa un cambio tecnológico y no puede ser considerado como una mera ampliación de la capacidad del sistema de transporte, como es el caso de la construcción de carreteras (Inglada, 2003).

Ante las numerosas dificultades existentes para acometer nuevas actuaciones en infraestructura, las aplicaciones SIT se muestran como una solución viable para hacer el movimiento de personas y mercancías más eficiente en todos los modos de transporte y especialmente en el carretero.

$\mathrm{Al}$ integrar las tres vías de información, comunicación y control, las tecnologías facilitan a las administraciones, operadores y usuarios estar mejor informados y poder tomar decisiones coordinadas (Inglada, 2003).

En Colombia, la industria del transporte goza de una importante participación en el PIB nacional y registra importantes crecimientos en los últimos años, producto de un crecimiento económico y específicamente en el petrolero; y esto se ve reflejado en el transporte de

1 SIT: Sistemas inteligentes de transporte 
equipo y herramientas que necesitan movilizar los proveedores del sector petrolero, ya que en el desarrollo de la bonanza de hidrocarburos que vivió el país hasta el año 2014 se pudo observar que la misma se encontraba en zonas bastante apartadas de los centros urbanos, por lo que sus vías de acceso, si no eran inexistentes se encontraban en precarias condiciones, y se ve reflejado en los altos costos logísticos, específicamente de transporte terrestre para ingresar a las zonas para iniciar los procesos de exploración y posteriormente de explotación y distribución de los hidrocarburos.

Colombia es el tercer productor de petróleo en Latinoamérica. Esto sumado al potencial boom petrolero que vivió el país y la creciente demanda local, convierte al país en un destino atractivo para la instalación de empresas dedicadas al suministro de bienes requeridos en la producción de hidrocarburos a pesar de los bajos precios de este commodity ${ }^{2}$.

El sector de servicios petroleros no atiende únicamente al sector de hidrocarburos, sino que "provee asistencia directa a sectores económicos clave como son la industria petrolera y gasífera y la generación, transporte y distribución de energía" (World Economic Forum, 2009). De igual manera, el sector responde a la creciente demanda de servicios de la minería en Colombia.

La industria petrolera tuvo una bonanza en los últimos años, lo cual género que sus necesidades en cuanto a equipo de exploración y explotación cada vez fueran mayores, máxime cuando los lugares donde se están realizando estos trabajos se encuentra en lugares de difícil acceso y deben adecuarse a las condiciones del terreno, por esto necesitan contar con aliados estratégicos y en especial en

2 Commodities: se hace énfasis en productos genéricos, básicos y sin mayor diferenciación entre sus variedades. 
el transporte de sus equipos y herramientas, ya que en este tipo de negocio cualquier retraso tiene costos muy elevados de millones de dólares (Fedesarrollo, 2012).

Por la misma sensibilidad de la explotación de petróleo las necesidades son más que urgentes, ya que se debe ejecutar un cronograma de producción con pólizas de cumplimiento.

Es este sentido que las empresas que se dedican a la prestación de servicios petroleros han utilizado sistemas inteligentes de información de transporte (SIT) para garantizar el acceso de los equipos petroleros al costo correcto, en el tiempo correcto, en el lugar correcto, al cliente correcto, en el estado correcto, del producto correcto, en la cantidad correcta, ya que de ello depende el éxito en la exploración y explotación de los hidrocarburos, que muy a pesar de estar atravesando una crisis por sus precios internacionales sigue siendo un factor de gran importancia en el desarrollo económico del país.

Como afirma Sánchez Rey (2001), la utilización de estas tecnologías reduce las emisiones contaminantes, el consumo de combustibles y los tiempos de viaje aumentando la confiabilidad de transporte.

En la mejora de los niveles de seguridad, cabe destacar entre las diferentes aplicaciones SIT a los sistemas de seguridad y vigilancia, junto a los sistemas de emergencias y aplicaciones específicas para los vehículos.

En el ámbito de los beneficios económicos cabe destacar a los sistemas de seguimiento de la mercancía y gestión de flotas que mejoran significativamente la eficiencia de las empresas logísticas.

En este momento, Colombia ya está ingresando en los SIT, y una prueba de ello es la implementación de peajes electrónicos, los cuales 
contribuyen eficazmente a la reducción de la congestión y a la mejora de la productividad, pero aún falta que el gremio del transporte carretero implemente cada vez más la utilización de los SIT para generar valor dentro de toda la cadena de abastecimiento.

Fiabilidad y variabilidad. Para el funcionamiento óptimo de los procesos just-in-time, el sistema de transporte, particularmente el transporte por carretera, desempeña un papel fundamental. En este sentido, la fiabilidad es el concepto clave que permite realizar previsiones sobre la duración del viaje con un mínimo margen de error. Con esta cualidad los fabricantes pueden gestionar eficientemente su nivel de stocks que es una de las características que definen los procesos (just-in-time).

También la fiabilidad en la estimación del tiempo de viaje es un concepto fundamental en el transporte de viajeros (Inglada, 2003).

Sinergias. Otro aspecto clave en la evaluación de los beneficios de las aplicaciones SIT es la existencia de importantes sinergias al combinar los diferentes sistemas. En este sentido, cabe destacar que la suma de los beneficios de las acciones integradas de SIT es superior a la suma de los beneficios correspondientes a cada aplicación por separado. Un ejemplo revelador de la existencia de estas sinergias corresponde a la integración de diferentes tecnologías SIT (información, pago electrónico, coordinación de horarios, etc.) en el transporte.

Como lo expresa Inglada (2003), gracias al uso eficiente de los SIT se logra gestionar todo lo referente a la planeación de viaje, así como poder atender oportunamente los incidentes que se puedan presentar en el mismo, ya que brinda información en tiempo real en cuanto a:

Gestión de la red vial, gestión de incidencias, gestión de emergencias, peaje electrónico, pago electrónico, información multimodal, 
sistemas integrados servicios de emergencia, gestión administrativa (permisos, etc.), gestión y seguimiento de la mercancía, ayuda al conductor; factores que le permiten al generador de carga tener control sobre la evolución del viaje.

Ya para terminar, las empresas prestadoras de servicios petroleros realizan contratos a mediano y largo plazo con las de transporte, provocando confianza entre generador de carga y empresa de transporte, al igual que con los transportadores permitiendo realizar inversiones en tecnologías que se ven reflejadas en un servicio con un valor agregado importante, controlando los riesgos y teniendo capacidad de reacción en tiempo real.

\section{CONCLUSIONES}

En Colombia existe una amplia legislación en el tema de transporte y especialmente en transporte carretero, pero por las características del negocio de transporte por carretera la mayoría de ella no se cumple por parte de los generadores de carga, las empresas de transporte y los transportadores.

Las empresas prestadoras de servicios petroleros se esfuerzan por contratar con empresas de transporte que les ofrezcan un valor agregado real y los Sistemas Inteligentes de Transporte se convierten en un factor diferenciador.

Existe un compromiso a mediano y largo plazo entre el prestador de servicios petroleros, las empresas de transporte y los transportadores basado en la confianza y solemnizado a través de contratos que 
brindan transparencia en el desarrollo de la actividad transportadora de equipo y material petrolero.

Los SIT se deben tomar como una inversión y no como un gasto, ya que los mismos les permiten aumentar la productividad a todos los integrantes de la cadena de suministro.

El gremio transportador se debe concientizar de que la competencia no se basa en los fletes, desmejorando los ingresos del sector, sino que se debe ofrecer un servicio con valor agregado.

El gobierno se encuentra interesado en aumentar la competitividad del país por medio del manejo adecuado de los costos de transporte, ya que el mismo impacta entre un 50\% y un 75\% del total de los costos logísticos de las empresas.

A través de los SIT se incrementa el rendimiento y la productividad de vehículos, carreteras y sistemas de transporte.

En un mundo globalizado es necesario que exista por parte de las empresas de transporte fiabilidad y variabilidad, que les permita ofrecer servicios a la medida de las necesidades de los clientes con soluciones innovadoras.

\section{BIBLIOGRAFÍA}

1. Cadena, N. (2013). El transporte de Carga por Carretera. Bogotá: Icono diseño y Publicidad. 
2. Cámara Colombiana de la Infraestructura. (2014). Colocación de Bonos y Financiamiento. Bogotá: Infraestructura y Desarrollo.

3. Cipoletta, G. (2010). Políticas integradas de infraestructura, transporte y logística. Serie recursos naturales.

4. Consejo Privado de Competitividad. (2015). Informe Nacional de Competitividad 2014-2015. Bogotá: Zetta Comunicaciones.

5. Consejo Privado de Competitividad. (2012). wrere.compite.com.co. Recuperado de: http://www.compite.com.co/site/wp-content/ uploads/2012/10/6-Infraestructura-Transporte-y-Logistica. pdf

6. Asecarga. (2013). El transporte de carga por carretera que Colombia necesita. El transporte de carga por carretera un modelo para exportar al mundo.

7. Ballou. (2004). Logistica Administración de la cadena de suministro. Naulcalpan de Juarez: Prentice Hall.

8. Fedesarrollo. (2012). Política de Proveedores del Sector Petrolero. Recuperado de: http://www.fedesarrollo.org.co/wp-content/ uploads/2011/08/Pol\%C3\%ADtica-de-proveedores-del-sector-petrolero-Informe-Final-Ismocol-Nov-2012.pdf

9. Inglada, V. (2003). Las nuevas tecnologias en el Transporte. Economía Industrial, 47-53. 
10. Ministerio de Transporte. (2005). Caracterización del Transporte en Colombia. Bogotá.

11. Ministerio de Transporte. (2013). Registro Unico Nacional de Transito. Bogotá.

12. Oficina Asesora de Planeación Min Transporte. (2005). Caracterización del Transporte en Colombia. Bogotá: Ministerio de Transporte.

13. Rey, A. S. (2001). Los Sistemas Inteligentes de Transporte. Obras publicas, 68-74.

14. Sanabria, S. (2008). El papel del transporte en el crecimiento económico colombiano en la segunda mitad del siglo XX. Apuntes CENES.

15. UIT. (2012). Impact of Broadband on Economic. Geneva: Unesco.

16. UIT. (2014). The state of broadband: Broadband. Geneva: Unesco.

17. WEF. (2014). Global Competitiveness Report. Geneva: World Economic Forum.

18. World Economic Forum. (2009). World Economic Forum. Recuperado de: http://www.weforum.org/ 
CAPÍTULO III

\section{TECNOLOGÍAS DE LA INFORMACIÓN Y LAS COMUNICACIONES - TIC}

Autor: Andrés Ignacio Zamudio Castro

\section{OBJETIV0}

"Las Tecnologías de la Información y de las Comunicaciones (TIC) son un elemento articulador entre los procesos de producción, distribución y disposición final en la cadena de abastecimiento, vinculando adicionalmente a los diferentes actores involucrados en los flujos de bienes e información tanto en la solicitud y recepción de pedidos, órdenes de servicios, transporte y almacenamiento de los bienes"

- (CONPES 3547). 
Teniendo en cuenta la definición anterior, en la cual se establece y se evidencia la importancia de las Tecnologías de la Información y de las Comunicaciones en la articulación de las actividades logísticas a nivel nacional, resulta comprensiva su categorización como uno de los subsistemas que se deben medir y evaluar para comparar el desempeño de la política nacional logística.

Adicionalmente, se ha evidenciado que la implementación de las Tecnologías de la Información y de las Comunicaciones en las organizaciones genera cambios en las estructuras y en las operaciones organizacionales, mejorando la eficiencia, reduciendo los costos e incrementando los ingresos.

Por otra parte, atendiendo la participación de Colombia en múltiples tratados comerciales, se evidencia el alto nivel de competitividad asociado con el comercio exterior. Esto requiere que se adopten nuevos mecanismos que permitan asegurar la información de las operaciones logísticas y, al mismo tiempo, permitan tener un claro conocimiento sobre los flujos transversales en las cadenas de suministro y abastecimiento.

\section{ALCANCE}

El alcance asociado con el subsistema de las Tecnologías de la Información y Comunicación se desarrolla en la generación de indicadores que permitan medir el desempeño de las variables y las políticas impulsadas por el gobierno nacional en materia de TIC. El objetivo de dichos indicadores está relacionado con el desarrollo e implementación de sistemas de información que permitan realizar el monitoreo del transporte de carga, impulsando actividades tales 
como tareas analíticas vinculadas a la caracterización de los ciclos y operaciones logísticas de transporte de carga, las relaciones entre los diferentes agentes logísticos que intervienen en la cadena. Dichos indicadores se deberán alimentar de nuevos sistemas de información o de los sistemas existentes con los que actualmente cuenta el sector logístico, como por ejemplo:

- Registro Nacional de Despachos de Carga (RNDG)

- Modelo de Oferta Vehicular (MOV)

- Índice de Costos del Transporte de Carga por Carretera (ICTC)

- Sistema de Información de Costos Eficientes (SICE TAC)

- Sistema de Información para la Regulación del Transporte de Carga por Carretera (SIRTCG)

\section{ANTECEDENTES}

De acuerdo con el documento 3547 generado por el Consejo Nacional de Política Económica y Social (CONPES), del Departamento Nacional de Planeación de la república de Colombia, "las políticas para el sector productivo estarán orientadas a incrementar el uso y apropiación de las Tecnologías de la Información y de las Comunicaciones en las empresas con el fin último de contribuir al aumento de la competitividad, y por ende a la productividad empresarial". 
Desde este punto de vista, el Gobierno Nacional busca promover la integración operacional entre los diferentes subsistemas (Urbano Territorial, Transporte e Infraestructura y Servicios Logísticos), medidos a partir de las diferentes categorías utilizadas para la evaluación de los sistemas logísticos a nivel nacional (Tiempos, Costos, Confiabilidad y Flexibilidad $)^{2}$ con las TIC, donde estas serán el eje articulador de las actividades logísticas a nivel nacional. Desde este punto de vista, lo que se busca es que todos los actores de las cadenas logísticas realicen sus operaciones bajo un ambiente confiable, predecible y eficiente, donde los flujos de información en las cadenas logísticas sean visibles y transparentes para cada uno de los actores involucrados, generando conectividad virtual y visibilidad de los procesos, permitiendo operaciones continuas, eficientes, seguras y de calidad, garantizando que los costos generados en dichas operaciones sean mínimos.

La importancia que le ha otorgado el Gobierno Nacional a las Tecnologías de la Información y de las Comunicaciones no solo se ha visto resaltada en el CONPES. Como uno de los ejes centrales del Plan Nacional de Tecnologías de la Información y de las Comunicaciones (PNTIC) 2008-2019, se busca promover la utilización de los sistemas de información y de comunicaciones en el sector productivo con la participación de las entidades públicas y privadas en los diferentes sectores empresariales.

Particularmente, la vinculación de las Tecnologías de la Información y de las Comunicaciones como eje articulador de los procesos logísticos está orientada al incremento de la productividad nacional, por medio de sistemas eficientes que permitan el

2 Tomado de "Best Practices In Corridor Managemet". Trade LogisTIC Group - The World Bank. 
- intercambio comercial de bienes y mercancías y el monitoreo de dichas actividades. Por lo tanto, se deberán diseñar, evaluar e implementar tecnologías cuyo objetivo sea:

- Sistemas de datawarehouse (almacenamiento y recuperación de datos)

- Rastreo y posicionamiento a mercancías y vehículos de transporte.

- Sistemas web para la consolidación de la oferta y demanda de servicios logísticos.

- Sistemas web para la consolidación de transacciones comerciales.

- "Sistemas enfocados a la simplificación de procedimientos administrativos ante autoridades de control de las operaciones de comercio exterior"3.

\section{PLAN NACIONAL DE TECNOLOGÍAS DE LA INFORMACIÓN Y LAS COMUNICACIONES (PNTIC) 2008-2019}

El Plan Nacional de Tecnologías de la Información y las Comunicaciones (PNTIC) es una "política de estado que tiene como principal objetivo contribuir a la inclusión social y la competitividad

3 Tomado de CONPES 3547. Departamento Nacional de Planeación (DNP). Octubre de 2008. 
del país, a través de estrategias que mejoren el uso y la apropiación de las tecnologías de la información y las comunicaciones (TIC)"4.

Dicho plan se concentra en ocho ejes o pilares básicos. De estos ocho ejes, cuatro se consideran ejes transversales, ya que cubren aspectos y programas que generan un impacto directo sobre la sociedad y la economía. Dichos ejes son:

- Comunidad - Acceso masificado a las TIC.

- Gobierno en línea.

- Investigación, desarrollo e innovación.

- Marco regulatorio e incentivos.

Los cuatro ejes restantes se consideran verticales, ya que se centran en sectores estratégicos, caracterizados así por el PNTIC. Dichos ejes son:

- Educación - incorporación de las TIC.

- Salud.

- Justicia.

- Competitividad Empresarial - Acciones orientadas a generar desarrollos en los sectores productivos del país.

4 Tomado de CONPES 3779. Departamento Nacional de Planeación (DNP). Octubre de 2013. 


\section{ACTORES DE LAS TECNOLOGÍAS DE LA INFORMACIÓN Y LAS}

COMUNICACIONES - TIC

Los principales actores del subsistema de las Tecnologías de la Información y de las Comunicaciones (TIC) son un conjunto de entidades gubernamentales y privadas, las cuales serán las encargadas de generar y suministrar la información de forma oportuna que alimentará el conjunto de indicadores desarrollados para la evaluación y el monitoreo del subsistema descrito.

Los actores relevantes para dicho objetivo son: 


\section{Actores gubernamentales}

\begin{tabular}{c|c} 
ACTOR & ¿CÓMO INCIDE EL ACTOR EN EL SISTEMA? \\
\hline Ministerio de & $\begin{array}{c}\text { Formulación y adopción de las políticas, planes, programas, } \\
\text { proyectos y regulación económica en materia de transporte, } \\
\text { tránsito e infraestructura de los modos de transporte carre- } \\
\text { tero, marítimo, fluvial, férreo y aéreo y la regulación técnica } \\
\text { en materia de transporte y tránsito de los modos carretero, } \\
\text { marítimo, fluvial y férreo. }\end{array}$ \\
\hline \multirow{2}{*}{$\begin{array}{c}\text { El Instituto Nacional de Vías - INVIAS es una agencia a cargo } \\
\text { de la asignación, regulación y supervisión de los contratos para } \\
\text { la construcción de carreteras y su respectivo mantenimiento. }\end{array}$}
\end{tabular}

Entre las principales responsabilidades, se puede mencionar:

1. Ejecuta la política del Gobierno Nacional en relación con la infraestructura de su competencia, de conformi-

Instituto Na-

cional de Vías

- INVIAS dad con los lineamientos establecidos por el Ministerio de Transporte.

2. Elabora conjuntamente con el Ministerio de Transporte los planes, programas y proyectos tendientes a la construcción, reconstrucción, mejoramiento, rehabilitación, conservación, atención de emergencias, y demás obras que requiera la infraestructura de su competencia.

3. Coordina con el Ministerio de Transporte la ejecución de los planes y programas de su competencia.

4. Adelanta investigaciones, estudios, y supervisa la ejecución de las obras de su competencia conforme a los planes y prioridades nacionales. 


\begin{tabular}{|c|c|}
\hline ACTOR & ¿CÓMO INCIDE EL ACTOR EN EL SISTEMA? \\
\hline & $\begin{array}{l}\text { "La Agencia Nacional de Infraestructura - ANI, es una agencia } \\
\text { gubernamental y tiene por objeto planear, coordinar, estruc- } \\
\text { turar, contratar, ejecutar, administrar y evaluar proyectos de } \\
\text { concesiones y otras formas de Asociación Público Privada - } \\
\text { APP, para el diseño, construcción, mantenimiento, operación, } \\
\text { administración y/o explotación de la infraestructura pública de } \\
\text { transporte en todos sus modos y de los servicios relacionados"5 }\end{array}$ \\
\hline
\end{tabular}

Agencia Na-

cional de In-

fraestructura

- ANI

Entre sus responsabilidades más relevantes se encuentran:

1. Identificar, evaluar la viabilidad y proponer iniciativas de concesión u otras formas de Asociación Público Privada para el desarrollo de la infraestructura de transporte y de los servicios relacionados.

2. Elaborar los estudios para definir los peajes, tasas, tarifas, contribución de valorización y otras modalidades de retribución por el diseño, construcción, operación, explotación, mantenimiento o rehabilitación de la infraestructura relacionada con los proyectos de concesión u otras formas de Asociación Público Privada.

Ministerio de

Tecnologías

de la Infor-

mación y Co-

municaciones

- MINTIC
El Ministerio de Tecnologías de la Información y las Comunicaciones es la entidad que se encarga de diseñar, adoptar y promover las políticas, planes, programas y proyectos del sector de las Tecnologías de la Información y las Comunicaciones.

Dentro de sus funciones está:

1. Diseñar, formular, adoptar y promover las políticas, planes, programas y proyectos del Sector de Tecnologías de la de la Información y, en correspondencia con la Constitución Política y la ley, con el fin de contribuir al desarrollo económico, social y político de la Nación y elevar el bienestar de los colombianos.

2. Impulsar el desarrollo y fortalecimiento del Sector de Tecnologías de la Información y las Comunicaciones, promover la investigación e innovación, buscando su competitividad y avance tecnológico conforme al entorno nacional e internacional. 


\section{Actores Privados}

\begin{tabular}{|c|c|}
\hline ACTOR & ¿CÓMO INCIDE EL ACTOR EN EL SISTEMA? \\
\hline $\begin{array}{l}\text { Operadores } \\
\text { de Transporte }\end{array}$ & $\begin{array}{l}\text { 1. Encargados del transporte de la carga desde los } \\
\text { puntos de origen a los puntos de destino de la } \\
\text { carga. } \\
\text { 2. Distribución y procesos de cargue y descargue. } \\
\text { 3. Velar por el adecuado transporte y su arribo a } \\
\text { tiempo }\end{array}$ \\
\hline $\begin{array}{l}\text { Operadores } \\
\text { Logísticos }\end{array}$ & $\begin{array}{l}\text { 4. Gestión y administración de plataformas logísticas } \\
\text { 5. Operación de servicios y terminales de carga. } \\
\text { 6. Promover las TIC como herramienta de control de } \\
\text { los flujos de información. }\end{array}$ \\
\hline
\end{tabular}




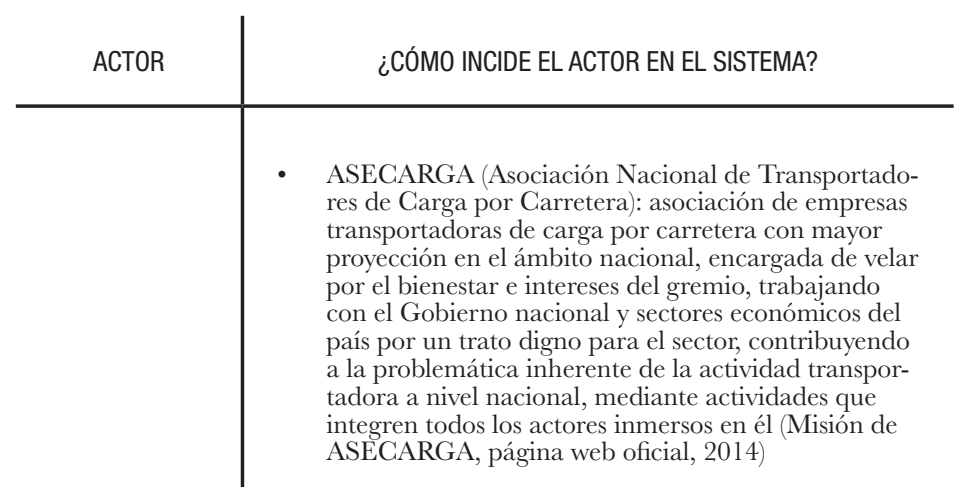

- COLFECAR: Federación Colombiana de Transportadores de Carga por Carretera: Desarrollar acciones gremiales con sentido de propuesta ante el Gobierno nacional.Intervenir propositivamente en la formulación del marco legal, estatutario y reglamentario de la actividad transportadora.

Velar por la promoción y desarrollo de los recursos humanos vinculados al sector transportador. Propiciar acuerdos con los usuarios para todos los fines de interés común y convivencia recíproca y coordinar a los federados en lo relativo a la explotación razo-

Agremiaciones

de Transporta-

dores - Sector

Privado nable de la actividad transportadora. Contribuir al desarrollo de programas de protección social para los afiliados (Objetivos de COLFECAR, página web oficial, 2014).

- ATC: Asociación de Transportadores de Carga: ejercer representación, vocería y asesoría al transporte de carga en territorio nacional e internacional, mediante estructura de una organización competente que disponga de recursos físicos y humanos para realizar investigación y propuestas comerciales en procura de la sostenibilidad y proyección de los transportadores de carga terrestres frente a los modelos económicos planteados en el país (Misión de la ATC, página web oficial, 2014).

- CGT: Confederación Colombiana de Transportadores.

- FEDETRANSCOL: Federación de Empresas Transportadoras de Carga por Carretera.

- ANDI: Asociación Nacional de Empresarios de Colombia.

- FENALCO: Federación Nacional de Comerciantes. 


\begin{tabular}{|c|c|}
\hline ACTOR & ¿CÓMO INCIDE EL ACTOR EN EL SISTEMA? \\
\hline & $\begin{array}{l}\text { El Ministerio de Tecnologías de la Información y las Comu- } \\
\text { nicaciones es la entidad que se encarga de diseñar, adoptar } \\
\text { y promover las políticas, planes, programas y proyectos del } \\
\text { sector de las Tecnologías de la Información y las Comu- } \\
\text { nicaciones. }\end{array}$ \\
\hline $\begin{array}{l}\text { Ministerio de } \\
\text { Tecnologías de }\end{array}$ & Dentro de sus funciones está: \\
\hline \multirow[t]{2}{*}{$\begin{array}{l}\text { la Información } \\
\text { y Comunica- } \\
\text { ciones - MIN- } \\
\text { TIC }\end{array}$} & $\begin{array}{l}\text { Diseñar, formular, adoptar y promover las políticas, } \\
\text { planes, programas y proyectos del Sector de Tecno- } \\
\text { logías de la de la Información y, en correspondencia } \\
\text { con la Constitución Política y la ley, con el fin de } \\
\text { contribuir al desarrollo económico, social y político } \\
\text { de la Nación y elevar el bienestar de los colombia- } \\
\text { nos. }\end{array}$ \\
\hline & $\begin{array}{l}\text { 2. Impulsar el desarrollo y fortalecimiento del Sector } \\
\text { de Tecnologías de la Información y las Comuni- } \\
\text { caciones, promover la investigación e innovación, } \\
\text { buscando su competitividad y avance tecnológico } \\
\text { conforme al entorno nacional e internacional. }\end{array}$ \\
\hline
\end{tabular}

\section{INDICADORES DEL SUBSISTEMA DE}

\section{TECNOLOGÍAS DE LA INFORMACIÓN Y}

\section{LAS COMUNICACIONES - TIC}

Los indicadores elaborados fueron desarrollados bajo la guía de formulación de indicadores del Departamento Nacional de Planeación y alineados con los objetivos estratégicos planteados inicialmente por el equipo de trabajo del proyecto E-Transcol, sobre el deber ser de la eficiencia de las Tecnologías de la Información y de las Comunicaciones (TIC) en las operaciones y actividades logísticas. 
Durante la etapa de diseño, se generaron un conjunto de indicadores los cuales fueron evaluados y depurados. Al mismo tiempo, y teniendo en cuenta diferentes variables, como la periodicidad de medición y la forma de calculo del indicador, se agrupó en un conjunto de familias denominadas Macro - Indicadores. Esto se realizó con el objetivo de obtener un conjunto de indicadores generales que permitieran evaluar el desempeño del subsistema de TIC, y que pudiera ser analizado de forma rápida y eficiente en un cuadro integral del mando, definiendo claramente los responsables del manejo de dicho ítem, así como la periodicidad de medición.

El conjunto de Macro Indicadores se presenta a continuación, con su respectiva descripción:

\section{Inversión media en TIC por tamaño de empresa del} sector logístico: este indicador se compone de dos elementos: las inversiones realizadas en TIC por clasificación de empresa y tamaño de la empresa (pyme, mediana o grande). Este indicador es de tipo cuantitativo y busca evaluar los recursos destinados a la implementación de TIC según el tamaño de la empresa y su cálculo esta basado en la ponderación de factores.

\section{Porcentaje de uso según tipología de TIC (GPS,} sistema de planificación, servicio de trazabilidad, sistemas transaccionales: Este indicador permite cuantificar en una escala relativa el uso de los diferentes tipos de TIC aplicados a las operaciones logísticas y busca evaluar el número de empresas que incluyen algún tipo de tecnología en sus operaciones. 
3. Vehículos con implementación de TIC para trazabilidad en entregas por corredor: este indicador permite cuantificar en una escala relativa el uso de los diferentes tipos de TIC aplicados a las operaciones logísticas y busca evaluar el número de vehículos que incluyen algún tipo de tecnología para la trazabilidad de las entregas.

4. Inversión anual en TIC (sector público + privado): este indicador permite cuantificar en una escala relativa la inversión anual realizada en TIC en los sectores públicos y privados frente a la inversión anual realizada por los sectores en operaciones logísticas.

5. Porcentaje de cobertura a nivel nacional para el monitoreo de mercancías: este indicador permite cuantificar en una escala relativa el nivel de cobertura a nivel nacional para el monitoreo de mercancías, dividido en los diferentes departamentos constituidos oficialmente.

6. Número de sistemas de información de servicios logísticos en operación: este indicador permite cuantificar en una escala absoluta el número de sistemas de información logísticos que se encuentran operando a nivel nacional, con el objetivo de evaluar la robustez de los sistemas logísticos a nivel nacional.

\section{Número de sistemas de información de servicios} logísticos desarrollados y en fase de prueba: este indicador permite cuantificar en una escala absoluta el número de sistemas de información logísticos que se encuentran en 
desarrollo y en fases de prueba, ya sea como complemento de los sistemas existentes o como nuevos sistemas de información logísticos.

8. Porcentaje de transacciones de consolidación de carga realizadas vía web: Este indicador permite cuantificar en una escala relativa la cantidad de procesos de consolidación de carga en los diferentes puntos de interconexión a nivel nacional.

\section{9. Índice de costos de transporte por medio de trans-} porte: este Indicador permite establecer un valor promedio de carga movilizada por cada uno de los modos de transporte existentes y utilizados en el territorio nacional.

A continuación, se presenta cada uno de estos Macro Indicadores, con su respectiva familia de indicadores utilizados para su resultado, así como las formas de cálculo, sus unidades de medida, la periodicidad y las entidades responsables de cada uno de estos:

\section{Inversión media en TIC por tamaño de empresa del} sector logístico: A continuación, se presenta la Información asociada a este indicador:

\begin{tabular}{c|l} 
Forma de cálculo del Macro Indicador & $\begin{array}{l}\text { Ponderación cualitativa de los el- } \\
\text { ementos que lo componen }\end{array}$ \\
\hline Unidad de medición del Macro Indicador & Porcentaje ponderado \\
\hline
\end{tabular}




\begin{tabular}{|c|c|}
\hline Forma de cálculo & $\begin{array}{l}\text { 1. Se debe promediar la } \\
\text { inversión total realizada } \\
\text { en TIC entre el número } \\
\text { de empresas del sector. } \\
\text { 2. Una vez obtenidos los } \\
\text { promedios, se realiza una } \\
\text { suma producto de los valo- } \\
\text { res promedio en inversión } \\
\text { entre el valor asignado a } \\
\text { cada grupo de empresas } \\
\text { por tamaño }\end{array}$ \\
\hline Unidad de medición & SCOP \\
\hline Viabilidad & SI \\
\hline Entidad que proporciona la información & INVIAS \\
\hline Periodicidad & Anual \\
\hline
\end{tabular}

Tabla 1 - Macro indicador 1 - Fuente: Propia

Entre las observaciones realizadas para la implementación de este Macro Indicador está determinar la manera como se le va a dar un valor cualitativo a los elementos que lo componen. Por lo tanto, la consolidación de este Macro Indicador, una vez obtenida la información, debe ser realizada por el Ministerio de Transporte.

\section{Porcentaje de uso según tipología de TIG (GPS,} sistema de planificación, servicio de trazabilidad, sistemas transaccionales: A continuación, se presenta la Información asociada a este indicador:

\begin{tabular}{l|l} 
Forma de cálculo del Macro Indicador & $\begin{array}{l}\text { Ponderación cualitativa de los el- } \\
\text { ementos que lo componen }\end{array}$ \\
\hline Unidad de medición del Macro Indicador & Porcentaje ponderado \\
\hline
\end{tabular}




\begin{tabular}{c|l}
\hline \multirow{2}{*}{ Forma de cálculo } & $\begin{array}{l}\text { Número de empresas con } \\
\text { utilización de sistemas GPS/ } \\
\text { Número de empresas totales }\end{array}$ \\
\cline { 2 - 2 } & $\begin{array}{l}\text { Número de empresas con } \\
\text { utilización de sistemas de plani- } \\
\text { ficación/Número de empresas } \\
\text { totales }\end{array}$ \\
\cline { 2 - 2 } & $\begin{array}{l}\text { Número de empresas con } \\
\text { utilización de servicios de tra- } \\
\text { zabilidad/Número de empresas } \\
\text { totales }\end{array}$ \\
\cline { 2 - 3 } Unidad de medición & $\begin{array}{l}\text { Número de empresas con siste- } \\
\text { mas transaccionales en línea/ } \\
\text { Número de empresas totales }\end{array}$ \\
\hline Viabilidad & Porcentual \\
\hline \multirow{2}{*}{ Entidad que proporciona la información } & SI \\
\hline
\end{tabular}

Tabla 2 - Macro indicador 2 - Fuente: Propia

Entre las observaciones realizadas para la implementación de este Macro Indicador está determinar la manera como se le va a dar un valor cualitativo a los elementos que lo componen. Por lo tanto, la consolidación de este Macro Indicador, una vez obtenida la información, debe ser realizada por el Ministerio de Transporte.

\section{Vehículos con implementación de TIC para trazabili-}

dad en entregas por corredor: A continuación se presenta la información asociada a este indicador: 


\begin{tabular}{c|l} 
Forma de cálculo del Macro Indicador & Porcentual \\
\hline Unidad de medición del Macro Indicador & Porcentual \\
\hline Forma de cálculo & $\begin{array}{l}\text { Número de vehículos con tec- } \\
\text { nologías de monitoreo/Número } \\
\text { de vehículos disponibles para la } \\
\text { movilización de carga }\end{array}$ \\
\hline Unidad de medición & Porcentual \\
\hline Viabilidad & SI \\
\hline Entidad que proporciona la información & INVIAS \\
\hline Periodicidad & Anual
\end{tabular}

Tabla 3 - Macro indicador 3 - Fuente: Propia

\section{Inversión anual en TIC (sector público + privado): A}

continuación se presenta la Información asociada a este indicador:

\begin{tabular}{c|l} 
Forma de cálculo del Macro Indicador & Porcentual \\
\hline Unidad de medición del Macro Indicador & Porcentual \\
\hline Forma de cálculo & $\begin{array}{l}\text { Total de Inversión realizada al } \\
\text { Año (público+privado) en TIC/ } \\
\text { Total de inversión realizada al } \\
\text { año (público+privado) en el } \\
\text { sector logístico }\end{array}$ \\
\hline Unidad de medición & Porcentual \\
\hline Viabilidad & SI \\
\hline
\end{tabular}




\begin{tabular}{c|l}
\hline Entidad que proporciona la información & $\begin{array}{l}\text { Ministerio de Transporte, INVIAS, } \\
\text { empresas privadas, Agencia Na- } \\
\text { cional de Infraestructura }\end{array}$ \\
\hline Periodicidad & Anual
\end{tabular}

Tabla 4 - Macro indicador 4 - Fuente: Propia

\section{Porcentaje de cobertura a nivel nacional para el moni-}

toreo de mercancías: A continuación se presenta la Infor-

mación asociada a este indicador:

\begin{tabular}{c|l} 
Forma de cálculo del Macro Indicador & $\begin{array}{c}\text { Ponderación cualitativa de los } \\
\text { elementos que lo componen }\end{array}$ \\
\hline Unidad de medición del Macro Indicador & Porcentaje ponderado \\
\hline Unidad de medición & $\begin{array}{l}\text { Total de kilómetros cuadrados } \\
\text { de cobertura en el departamen- } \\
\text { to } / \text { Total de kilómetros cuadra- } \\
\text { dos del total departamental }\end{array}$ \\
\hline Viabilidad & Porcentual \\
\hline Entidad que proporciona la información & INVIAS \\
\hline Periodicidad & Anual
\end{tabular}

Tabla 5 - Macro indicador 5 - Fuente: Propia

Nuevamente, entre las observaciones realizadas para la implementación de este Macro Indicador está determinar la manera como se le va a dar un valor cualitativo a los elementos que lo componen. Por 
lo tanto, la consolidación de este Macro Indicador, una vez obtenida la información, debe ser realizada por el Ministerio de Transporte.

\section{Número de sistemas de información de servicios} logísticos en operación: A continuación se presenta la Información asociada a este indicador:

\begin{tabular}{c|l} 
Forma de cálculo del Macro Indicador & $\begin{array}{l}\text { Sumatoria de las variables aso- } \\
\text { ciadas }\end{array}$ \\
\hline Unidad de medición del Macro Indicador & Numérico \\
\hline Forma de cálculo & $\begin{array}{l}\text { Sumatoria del Número de Siste- } \\
\text { mas de Información Operativos } \\
\text { en el año }\end{array}$ \\
\hline Unidad de medición & Unidades \\
\hline Viabilidad & SI \\
\hline Entidad que proporciona la información & Ministerio de Transporte \\
\hline Periodicidad & Anual
\end{tabular}

Tabla 6 - Macro indicador 6 - Fuente: Propia

\section{Número de sistemas de información de servicios lo-} gísticos desarrollados y en fase de prueba: A continuación se presenta la Información asociada a este indicador: 


\begin{tabular}{c|l}
\hline Unidad de medición del Macro Indicador & Numérico \\
\hline Forma de cálculo & $\begin{array}{l}\text { Sumatoria del número de } \\
\text { sistemas de información en } \\
\text { desarrollo o en fases de prueba } \\
\text { en el año }\end{array}$ \\
\hline Unidad de medición & Unidades \\
\hline Viabilidad & SI \\
\hline Entidad que proporciona la información & $\begin{array}{l}\text { Ministerio de Transporte, RUNT, } \\
\text { sector privado y educativo }\end{array}$ \\
\hline Periodicidad & Anual
\end{tabular}

Tabla 7 - Macro indicador 7 - Fuente: Propia

\section{Porcentaje de transacciones de consolidación de carga} realizadas vía web: A continuación se presenta la Información asociada a este indicador:

\begin{tabular}{c|l} 
Forma de cálculo del Macro Indicador & Porcentual \\
\hline Unidad de medición del Macro Indicador & Porcentual \\
\hline Forma de cálculo & $\begin{array}{l}\text { Número de transacciones de } \\
\text { consolidación de carga vía web } \\
\text { o sistemas logísticos transaccio- } \\
\text { nales sobre el número de viajes } \\
\text { realizados en consolidación }\end{array}$ \\
\hline Unidad de medición & Porcentual \\
\hline Viabilidad & SI \\
\hline
\end{tabular}




\begin{tabular}{c|l}
\hline Entidad que proporciona la información & $\begin{array}{l}\text { Ministerio de Transporte, RNDC, } \\
\text { sector privado }\end{array}$ \\
\hline Periodicidad & Anual
\end{tabular}

Tabla 8 Macro indicador 8 - Fuente: Propia

\section{9. Índice de costos de transporte por medio de transpor-}

te: A continuación se presenta la Información asociada a este indicador:

\begin{tabular}{|c|c|}
\hline Forma de cálculo del Macro Indicador & Costo total por modo de transporte \\
\hline Unidad de medición del Macro Indicador & Numérico \\
\hline Forma de cálculo & $\begin{array}{l}\text { Costo total de los viajes realiza- } \\
\text { dos en el mes por modo de trans- } \\
\text { porte / Número de viajes realiza- } \\
\text { dos por modo de transporte }\end{array}$ \\
\hline Unidad de medición & SCOP \\
\hline Viabilidad & SI \\
\hline Entidad que proporciona la información & $\begin{array}{l}\text { Ministerio de Transporte, INVIAS, } \\
\text { empresas privada }\end{array}$ \\
\hline Periodicidad & Mensual \\
\hline
\end{tabular}

